\title{
Results of large scale media antismoking campaign in Australia: North Coast "Quit for Life" programme
}

\author{
G EGGER，W FITZGERALD， G FRAPE， A MONAEM， P RUBINSTEIN，C TYLER， B McKAY
}

\begin{abstract}
A three community study was carried out in northern New South Wales, Australia, to determine the effectiveness of interventions via media and media plus community programmes in altering behaviours of life style, including smoking, dietary fat intake, and exercise. Results were analysed of one aspect of the "North Coast Healthy Lifestyle Programme" entitled "Quit for Life," which aimed at reducing cigarette smoking over a two year period.

There was a significant decline in the prevalence of smoking in both test towns, ranging from $16 \%$ in younger men to $6 \%$ in older women. These were significantly greater than the declines in the control town. The declines were more sustained over the two year period in the town subjected to media plus community programmes.
\end{abstract}

\section{Introduction}

Smoking was first implicated in the 1950 s as a risk factor for lung cancer. ${ }^{1}$ Since then it has been linked with cardiovascular disease and cancers of the mouth, trachea, oesophagus, and digestive tract. ${ }^{2}$ As a result a wide range of health education programmes aimed at reducing smoking have arisen, ${ }^{3}$ but although there have been some declines in the prevalence of smoking in certain Western countries-related apparently to various events and campaigns ${ }^{4}$ - so far there has been little cause for optimism.

In a comprehensive review of antismoking education programmes carried out over 16 years, Thompson concluded that no single technique of health education had been entirely successful. ${ }^{3}$ In reviewing multifaceted approaches, however, Pechacek suggested that worthwhile reductions are possible "when the risks of smoking are made more immediate and salient, and both skills and support to change are provided." 5

Large scale health promotion programmes using this approach are currently being attempted in at least six countries. ${ }^{6}$ So far,

Health Department of New South Wales, Sydney, Australia

G EGGER, BA, PHD, senior research scientist

W FITZGERALD, BA, consultant

G FRAPE, media, director, journalist, consultant

A MONAEM, MSC, MPH, research officer

P RUBINSTEIN, BA, MA, programme director

C TYLER, BCOMM, MEDADMIN, administration director

B MCKAY, secretary

Correspondence to: Dr G Egger, Centre for Health Promotion and Research, Sydney 2000, New South Wales, Australia. successes in modification of smoking using both the media and skills training have been reported from North Karelia in Finland ${ }^{7}$ and Stanford University in California. ${ }^{8}$ In Finland, after a study carried out over five years, reductions in smoking prevalence from around $50 \%$ to $40 \%$ occurred in a test community, but these were confounded by major national legislative changes which contributed to similar reductions in a control community. There was, however, a net absolute reduction of around $9 \%$ in the numbers of cigarettes smoked in the test community during the trial period.

In the Stanford study a three town design was chosen. In one test town only media based inputs were used, and in a second town the media were combined with community programmes. The effects in both test towns were compared with those in a control town. After two years the proportion of smokers had decreased by a net $5.5 \%$ in the media plus community programmes town, suggesting a positive role for the media in health risk behaviour intervention. In 1980 the Stanford researchers extended their analysis to a major five town study of the role of the media in heart disease risk factor intervention.

In Australia the "North Coast Healthy Lifestyle Programme" was set up in 1978 to test over two years the effects of the media alone and media plus community programmes on life style. The programme was funded jointly by the NSW Health Department and the Commonwealth Department of Health. As at Stanford, a three town quasi-experimental design was chosen. The stated aims of the study were $(a)$ to decrease the prevalence of smoking, (b) to increase participation in physical activity, and (c) to reduce the consumption of dietary fat. We report the results in respect of objective $(a)$, the antismoking component of the healthy lifestyle programme, called the "Quit for Life" campaign.

Intervention in previous large scale health promotion media campaigns has generally utilised the communication-behaviour change framework. ${ }^{6}$ This entails using the media to deliver information on which the receiver can rationally act or not act. An alternative-that used here-is the social marketing approach, described by Kotler and Zaltman as ". . . the explicit use of marketing skills to help translate present social efforts into more effectively designated and communicated programmes that elicit desired audience response."10 More recently Solomon has discussed the advantages of social marketing in public communication campaigns. ${ }^{11}$

The North Coast Healthy Lifestyle Programme used professional commercial media and advertising techniques to prepare media messages. Because of the limited time scale of the programme it was primarily orientated towards change in behaviour rather than eventual health outcomes of such change, and the measures of evaluation used reflected this emphasis. Both quantitative and qualitative evaluation techniques were used. The former included three large scale surveys of sample populations. The latter (focus groups, spot surveys, etc) were carried out at regular intervals to assess the effectiveness of the intervention techniques used. 


\section{Methods}

Three communities on the north coast of New South Wales, Australia (500-700 km north of Sydney), were chosen for the study in 1978. These were Lismore (population 22 083), Coffs Harbour (12 197), and Tamworth (27 280). Because they shared a television station, Lismore and Coffs Harbour were chosen as test townsLismore being chosen to test the combined effect of media plus community programmes and Coffs Harbour to test the media programme alone. Tamworth was chosen as a control region because it had a separate media network and was in a different administrative health region.

\section{INTERVENTION TECHNIQUES}

\section{Media}

Media included television (a shared station in Lismore and Coffs Harbour), radio (a local station in Lismore and a relay station in Coffs Harbour, which shared its facilities with a town further south of Coffs Harbour), print (one paid circulation local daily newspaper in Lismore and one smaller local triweekly newspaper plus a weekly free paper in Coffs Harbour), stickers, posters, T shirts, balloons, and self help "Quit" kits. Advertisements in the media were paid for so that advertising time and space could be predetermined and seen at peak viewing periods. An equal amount of time was, however, donated free by the stations. Other media were made available in the form of editorial space, features, news releases, radio interviews, television appearances, weekly programmes, retail advertising, and pictorial spreads.

The planned media input of the Quit for Life programme was carried out in three stages-(1) a general awareness stage, (2) an information stage, (3) a "positive affect" creation stage. Stage 1 was part of a nine week campaign designed to introduce the healthy lifestyle programme. Stages 2 and 3 were run for a total of 31 weeks during the campaign.

All advertisements in the media were professionally created, pretested, produced, and evaluated. Television commercials were entertaining and controversial, one winning an advertising industry award. All printed advertisements were suspended for 15 weeks from October 1979 (four months after the start of the antismoking campaign) after complaints to the Media Council of Australia by the three major tobacco manufacturers. One television commercial was also suspended pending change in wording. All complaints concerned issues of disparaging copy. After minor changes, however the commercials were allowed to run. The case generated nationwide publicity (which was received in the control town). Further details of the ban have been documented elsewhere. ${ }^{12}$

\section{Community programmes}

There was a variety of community programmes in Lismore, ranging from skills training to a "Lifestyle" shop. Tables I and II show the programmes, numbers concerned, and estimated success rates. The programmes included quit smoking groups, kits handed out by doctors, aids to help smokers quit, and "Quit" fact sheets. Success rates were gauged by follow up interviews three months after the completion of media advertising. In addition, there were other activities such as fun runs, computerised health testing, and stress management training which, although part of the overall healthy lifestyle programme, were related to the quit for life campaign.

\section{Evaluation}

To assess the effects of the intervention a baseline survey in 1978 (year 1) and two later follow up surveys in 1980 (year 2) and 1981 (year 3) were carried out with a systematic random sample of men and women aged 18 years and over from each community. The surveys included a physiological examination and questionnaire interview carried out by a trained interviewer at a central screening centre. Those selected in the sample who either did not respond to three separate screening appointments or did not wish to undertake the full screening were asked to complete the same interview at home.

The study sample consisted of up to two adults per household from households selected at random. Where there were more than two adults in a household a predetermined procedure was used to select those to be included in the study. For year 1 the sampling procedure was de- signed to select about 600 adults per town. In years 2 and 3 sample sizes were increased to about 1000 adults per town.

Follow up samples (years 2 and 3 ) consisted of subsamples of those previously screened plus a new randomly selected sample. This report considers responses only in relation to smoking for the independent samples. Further analysis is to be carried out on the responses of people sampled more than once.

The questionnaire included attitudes to smoking (six questions), knowledge of the effects of smoking (six questions), and smoking behaviour (four questions). Interviews were conducted by trained interviewers, most of whom travelled to each town at each measure-

TABLE I-Numbers concerned in community antismoking programmes from Quit for Life campaign

\begin{tabular}{lcc}
\hline & No of smokers & $\begin{array}{c}\text { Estimated success } \\
\% \text { abstinence after three months } \\
\text { as measured by telephone } \\
\text { questionnaire) }\end{array}$ \\
\hline 5 Day plan & 14 & $28 \cdot 6$ \\
Commercial groups & 65 & $\mathrm{NA}$ \\
"Quit", club & 48 & $23 \cdot 0$ \\
"Quit", 1 day workshop & 150 & $16 \cdot 0$ \\
"Quit" 5 day clinics & 24 & $23 \cdot 0$ \\
Hypnotherapy groups & 45 & $\mathrm{NA}$ \\
Doctors' kits & 40 & $48 \cdot 0$ \\
\hline Total & 386 & $23 \cdot 1$ (estimate) \\
\hline
\end{tabular}

$\mathrm{NA}=\mathrm{Not}$ assessed

TABLE II-Numbers concerned in media antismoking programmes from Quit for Life campaign

\begin{tabular}{lcc}
\hline & $\begin{array}{c}\text { No purchased or } \\
\text { distributed }\end{array}$ & $\begin{array}{c}\text { Estimated success } \\
\% \text { abstinence after three months } \\
\text { as measured by telephone } \\
\text { questionnaire) }\end{array}$ \\
\hline "Quit" kits & 1500 & $17 \cdot 0$ \\
"Quit" fact sheets & 6000 & NA \\
"Quitter Tips"pack & 200 & NA \\
"Quitline" telephone message & 5800 & NA
\end{tabular}

$\mathrm{NA}=$ Not assessed

TABLE III-Sample statistics

\begin{tabular}{lccc}
\hline & Lismore & Coffs Harbour & Tamworth \\
\hline Year 1 (1978): & & & \\
Total sample & 601 & 612 & 589 \\
Total response rate & $69 \%$ & $71 \%$ & $72 \%$ \\
Questionnaire only & $253 \%$ & 244 & 221 \\
Year 2 (1980): & & & \\
Total sample & 1278 & 1272 & 1239 \\
Total response rate & $153^{\circ}$ & $73 \%$ & $74 \%$ \\
Questionnaire only & 165 & 222 & $132 \%$ \\
Repeat sample only & & & 249 \\
Year 3 (1981): & 1152 & 1195 & 1195 \\
Total sample & $70^{\circ}{ }^{\circ}$ & $73 \%$ & $74 \%$ \\
Total response rate & 281 & $277 \%$ & 283 \\
Questionnaire only & 276 & 302 & 274 \\
Repeat sample only & & &
\end{tabular}

ment period. There was, however, some turnover of interviewers from year to year. Physiological examination included measurements of height, weight, blood pressure and pulse rate, and the collection of a blood sample. The examinations were conducted by specially trained nurses operating from the central screening centre in each town.

In years 2 and 3 plasma analyses included measurement of the sodium thiocyanate concentration to validate responses from a randomly selected 5\% subsample. Thiocyanate estimations indicated that less than $3 \%$ of responses to questions concerning smoking behaviour in all three towns were invalid. There were no significant differences among the three towns in thiocyanate discrepancies.

Table III shows the sample numbers and response rates. Three main outcome measures reported here are self reported smoking behaviour, attitudes to smoking, and knowledge of the health effects of smoking. 
TABLE IV-Adjusted percentage rates of prevalence of smoking by town, year, age, and sex. (Unadjusted baseline percentage given in parentheses)

\begin{tabular}{|c|c|c|c|c|c|c|c|c|c|c|c|c|}
\hline \multirow{2}{*}{$\begin{array}{l}\text { Age } \\
\text { (years) }\end{array}$} & \multicolumn{4}{|c|}{ Lismore } & \multicolumn{4}{|c|}{ Coffs Harbour } & \multicolumn{4}{|c|}{ Tamworth } \\
\hline & Baseline & Year 2 & Year 3 & $\mathrm{D}^{*}$ & Baseline & Year 2 & Year 3 & $\mathrm{D}^{*}$ & Baseline & Year 2 & Year 3 & $\mathrm{D}^{*}$ \\
\hline \multicolumn{13}{|c|}{ Men } \\
\hline $\begin{array}{l}18-25 \\
26-35 \\
36-45 \\
46-55 \\
56-65 \\
>65\end{array}$ & $\begin{array}{l}58 \cdot 3(49 \cdot 5) \\
50 \cdot 4(52 \cdot 0) \\
46.6(45 \cdot 2) \\
37.6(38.9) \\
35.9(34.5) \\
21.8(22 \cdot 5)\end{array}$ & $\begin{array}{l}46 \cdot 0 \\
38 \cdot 2 \\
34 \cdot 7 \\
26 \cdot 9 \\
25 \cdot 5 \\
14 \cdot 5\end{array}$ & $\begin{array}{l}42 \cdot 6 \\
35 \cdot 0 \\
31 \cdot 6 \\
24 \cdot 2 \\
22 \cdot 9 \\
12 \cdot 9\end{array}$ & $\begin{array}{r}15 \cdot 7 \\
15 \cdot 4 \\
14 \cdot 0 \\
13 \cdot 4 \\
13 \cdot 0 \\
8 \cdot 9\end{array}$ & $\begin{array}{l}51 \cdot 9(59 \cdot 2) \\
42.7(46 \cdot 2) \\
43.3(48 \cdot 1) \\
41.8(38 \cdot 7) \\
38.5(37 \cdot 5) \\
23.2(22 \cdot 4)\end{array}$ & $\begin{array}{l}37 \cdot 8 \\
29 \cdot 6 \\
30 \cdot 1 \\
28 \cdot 8 \\
26 \cdot 1 \\
14 \cdot 5\end{array}$ & $\begin{array}{l}40 \cdot 7 \\
32 \cdot 2 \\
32 \cdot 7 \\
31 \cdot 4 \\
28 \cdot 5 \\
16 \cdot 1\end{array}$ & $\begin{array}{r}11 \cdot 2 \\
10 \cdot 5 \\
10 \cdot 6 \\
10 \cdot 4 \\
10 \cdot 0 \\
7 \cdot 1\end{array}$ & $\begin{array}{l}63 \cdot 1(58 \cdot 1) \\
40 \cdot 2(38 \cdot 1) \\
46 \cdot 5(42 \cdot 8) \\
46 \cdot 4(46 \cdot 8) \\
43 \cdot 6(43 \cdot 5) \\
30 \cdot 2(34 \cdot 3)\end{array}$ & $\begin{array}{l}58 \cdot 4 \\
35 \cdot 6 \\
41 \cdot 6 \\
41 \cdot 5 \\
38 \cdot 8 \\
26 \cdot 3\end{array}$ & $\begin{array}{l}58 \cdot 1 \\
35 \cdot 4 \\
41 \cdot 4 \\
41 \cdot 3 \\
38 \cdot 6 \\
26 \cdot 1\end{array}$ & $\begin{array}{l}5 \cdot 0 \\
4 \cdot 8 \\
5 \cdot 1 \\
5 \cdot 1 \\
5 \cdot 0 \\
4 \cdot 1\end{array}$ \\
\hline \multicolumn{13}{|c|}{ Women } \\
\hline $\begin{array}{l}18-25 \\
26-35 \\
36-45 \\
46-55 \\
56-65 \\
>65\end{array}$ & $\begin{array}{l}53 \cdot 3(59 \cdot 1) \\
32 \cdot 7(30 \cdot 5) \\
28 \cdot 9(34 \cdot 3) \\
24 \cdot 9(20 \cdot 0) \\
24 \cdot 5(20 \cdot 9) \\
14 \cdot 2(18 \cdot 0)\end{array}$ & $\begin{array}{r}41 \cdot 0 \\
22 \cdot 9 \\
19 \cdot 8 \\
16 \cdot 8 \\
16 \cdot 5 \\
9 \cdot 1\end{array}$ & $\begin{array}{r}37 \cdot 7 \\
20 \cdot 5 \\
17 \cdot 7 \\
14 \cdot 9 \\
14 \cdot 7 \\
8 \cdot 0\end{array}$ & $\begin{array}{r}15 \cdot 6 \\
12 \cdot 2 \\
11 \cdot 2 \\
10 \cdot 0 \\
9 \cdot 8 \\
6 \cdot 1\end{array}$ & $\begin{array}{l}49.4(43.2) \\
44.9(38.9) \\
37.1(37.0) \\
34.0(31.0) \\
29.6(35.1) \\
18.9(21.5)\end{array}$ & $\begin{array}{l}35 \cdot 5 \\
31 \cdot 5 \\
24 \cdot 9 \\
22 \cdot 5 \\
19 \cdot 2 \\
11 \cdot 6\end{array}$ & $\begin{array}{l}38 \cdot 3 \\
34 \cdot 2 \\
27 \cdot 3 \\
24 \cdot 7 \\
21 \cdot 1 \\
12 \cdot 9\end{array}$ & $\begin{array}{r}11 \cdot 1 \\
10 \cdot 7 \\
9 \cdot 8 \\
9 \cdot 3 \\
8 \cdot 5 \\
6 \cdot 0\end{array}$ & $\begin{array}{l}47 \cdot 3(42 \cdot 6) \\
32 \cdot 8(32 \cdot 0) \\
36 \cdot 2(34 \cdot 6) \\
30 \cdot 4(29 \cdot 8) \\
20 \cdot 7(22 \cdot 4) \\
12 \cdot 2(10 \cdot 0)\end{array}$ & $\begin{array}{l}42 \cdot 4 \\
28 \cdot 6 \\
31 \cdot 8 \\
26 \cdot 4 \\
17 \cdot 7 \\
10 \cdot 2\end{array}$ & $\begin{array}{l}42 \cdot 2 \\
28 \cdot 4 \\
31 \cdot 6 \\
26 \cdot 2 \\
17 \cdot 5 \\
10 \cdot 1\end{array}$ & $\begin{array}{l}5 \cdot 1 \\
4 \cdot 4 \\
4 \cdot 6 \\
4 \cdot 0 \\
3 \cdot 2 \\
2 \cdot 1\end{array}$ \\
\hline
\end{tabular}

* $\mathrm{D}=$ Difference between baseline value and value at year 3 .

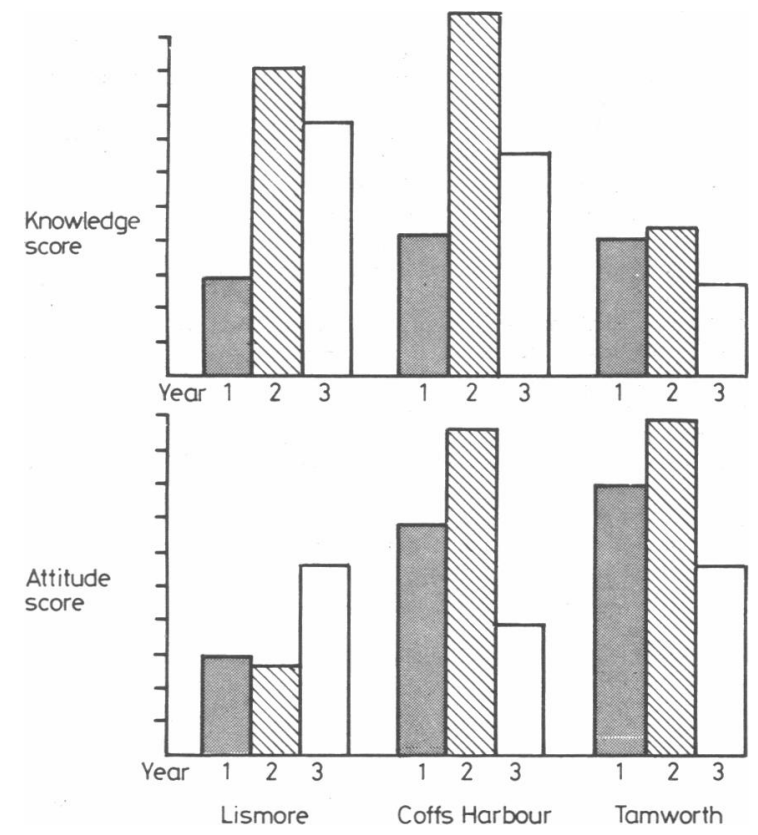

Mean scores for smoking knowledge and attitudes to smoking in three towns by year. Increases show improvements in desired direction.

\section{Results}

Analysis of figures for the prevalence of smoking was carried out with a multiple logistic regression model via the computer package GLIM3. ${ }^{13}$ It was known a priori that there was a substantial confounding of the three sample surveys $(1978,1980,1981)$ owing to age and sex differences both across towns and years. In modelling these response data it was found necessary to include as the first term an AGE * SEX * TOWN term to account for confounding. Next the temporal factor (YEAR) was fitted before the treatment effect TOWN * YEAR was allowed to enter. The goodness of fit of the model was further reinforced by an extensive examination of the residuals.

In table IV smoothed prevalence rates for each year of the study are shown in the columns marked "Baseline," "Year 2," and "Year 3." The difference between baseline and year 3 is shown in the column marked "D." The figures summarise the results of the study and are the sum of the temporal effect (year) and the treatment effect (town $\times$ year). The effect was statistically significant $\left(\chi^{2}=60.34 ; \mathrm{df}=6\right.$; $\mathrm{p}<0.05$ ).

The biggest changes in the prevalence of smoking occurred in Lismore, with declines ranging from $15.7 \%$ (men aged 18-25) to $6.1 \%$ (women aged over 65). Declines in year 2 in Coffs Harbour were offset by an increase in prevalence in year 3 , resulting in a decline over the two years of between $6 \%$ and $11 \%$. For the control town (Tamworth) there was a small decrease in smoking prevalence of between $2 \%$ and $5 \%$.

These results (table IV) suggest that the Quit for Life programme was effective in reducing the prevalance of smoking in the two test towns. The most consistent effect was in the media and programmes town (Lismore). The figure shows the mean scores for smoking knowledge and attitude to smoking in each town over the test period.

Analysis of variance was used to test the significance of the differences between the mean attitude and knowledge scores by town, year, age, and sex. This analysis consistently produced poor fits to the data as reflected by a maximum $r^{2}$ of $0 \cdot 06$. Hence no statistically substantive results can be reported on these issues.

Smokers in each town who had quit the habit were asked how they quit and who or what had influenced them most significantly in their decision to quit. Tables $\mathrm{V}$ and VI give the percentage responses for each town. Most of those quitting in all three towns had done so without help, either by stopping suddenly or by slowly reducing (table V). There were small percentages in the test towns who claimed to have been helped by self help kits or group programmes. Surprisingly, the latter were also present in Coffs Harbour, the media only town, suggesting that community quit smoking programmes may have been operating independently of the Quit for Life programme.

Reported influences in the decision to quit smoking included a small effect of social pressure and media advertisements in the test towns, particularly Lismore (table VI). Overall, however, health concerns appeared to be the major factor.

TABLE V-Reported techniques of quitting (in year 3) by those quitting smoking in three towns

\begin{tabular}{|c|c|c|c|c|c|c|}
\hline & \multicolumn{2}{|c|}{ Lismore } & \multicolumn{2}{|c|}{ Coffs Harbour } & \multicolumn{2}{|c|}{ Tamworth } \\
\hline & No & $\%$ & No & $\%_{0}$ & No & $\%$ \\
\hline $\begin{array}{l}\text { "Cold turkey" } \\
\text { Slowly cutting back } \\
\text { Self help kits } \\
\text { Group programme } \\
\text { Hypnosis } \\
\text { Other }\end{array}$ & $\begin{array}{r}171 \\
3 \\
2 \\
1 \\
4 \\
17\end{array}$ & $\begin{array}{r}86 \\
2 \\
1 \\
1 \\
2 \\
9\end{array}$ & $\begin{array}{r}179 \\
4 \\
4 \\
3 \\
4 \\
11\end{array}$ & $\begin{array}{r}87 \\
2 \\
2 \\
1 \\
2 \\
5\end{array}$ & $\begin{array}{r}144 \\
3\end{array}$ & $\begin{array}{r}87 \\
2\end{array}$ \\
\hline
\end{tabular}

TABLE VI-Reported influences in decision to quit

\begin{tabular}{|c|c|c|c|c|c|c|}
\hline & \multicolumn{2}{|c|}{ Lismore } & \multicolumn{2}{|c|}{ Coffs Harbour } & \multicolumn{2}{|c|}{ Tamworth } \\
\hline & No & $\%$ & No & $\%$ & No & $\%$ \\
\hline $\begin{array}{l}\text { Friends/family } \\
\text { Social pressure } \\
\text { Media advertisements } \\
\text { Health concerns } \\
\text { Doctor's advice } \\
\text { Other }\end{array}$ & $\begin{array}{r}27 \\
5 \\
11 \\
91 \\
10 \\
54\end{array}$ & $\begin{array}{r}14 \\
3 \\
6 \\
46 \\
5 \\
27\end{array}$ & $\begin{array}{r}30 \\
2 \\
5 \\
108 \\
14 \\
46\end{array}$ & $\begin{array}{r}15 \\
1 \\
2 \\
53 \\
7 \\
22\end{array}$ & $\begin{array}{r}21 \\
1 \\
2 \\
99 \\
8 \\
36\end{array}$ & $\begin{array}{r}13 \\
1 \\
1 \\
59 \\
5 \\
22\end{array}$ \\
\hline
\end{tabular}

\section{Discussion}

The declines in prevalence of smoking in the test towns support findings from other large scale programmes of media intervention. ${ }^{78}$ Prevalence was reduced during the first intervention period in both test towns. When media were combined with community programmes the reduction continued into the second intervention period. 
As in the Stanford three town study ${ }^{7}$ smoking prevalence in the media only town decreased in the first year of the study and then increased slightly. The net reductions in prevalence in this study were of the same order as achieved by the Stanford group-that is, $2-5 \%$.

As with any non-randomised trial it is difficult to separate the treatment effect from coincidental extraneous factors in the study regions. For example, there are several extraneous factors which should be noted in interpreting the results. Firstly, this study was affected by the suspension by the Media Council of Australia of advertisements used in the campaign. Not only were antismoking advertisements stopped for some 15 weeks at a crucial time in the campaign but national interest and publicity were stimulated, including in the control town. Possibly this as well as any "Hawthorn" effect may explain decreases in smoking in the control town in excess of the national average, which was around $1 \%$ in the test period. ${ }^{14}$

It is not clear in which direction the banning would have affected results in the test towns. The loss of impact of the campaign in year 3 in the media only town (Coffs Harbour) may have been due simply to a reduction in media effort. There may however, have been other factors intrinsic to the design of the project. For example, although an attempt was made to balance media exposure in both test towns, community programmes generate their own media, especially if they are successful, because they become news. The synergistic effect of community programmes is therefore likely to be far greater than the effect of the programmes themselves.

Of the quit smoking programmes offered, the most popular were those that did not require face to face contact-that is, kits, information brochures, fact sheets, etc. Quite possibly face to face groups did not recruit great numbers because the social climate created by the media in Lismore was such as to act against smokers declaring themselves in public. This point is important for future campaigns, because, as has been noted here, although the success rate of media campaigns may be less than that of community programmes, the success of the former more than compensates for this in terms of total numbers successfully quitting.

There were no significant changes in attitude and knowledge about smoking in the test towns, and hence those results are not reported here. Variability in sample characteristics between the test years may have contributed to the difficulty in interpreting these results.

It is important to know which aspect of the campaign had most impact and with which target groups. Qualitative evaluation, not reported in detail here, suggested the following: (1) informational print media using a mild "fear arousal" approach had little effect on smokers but was noticed by those who already had a concern about their health (the most effective print advertisements related to the cosmetic-for example, wrinkled skin-and social-bad breath-consequences of smoking); (2) on electronic media, an emotional "fear" approach which was light hearted, entertaining, and with suggested advice for action had a powerful impact on smokers; (3) the "positive affect" or image based approach on electronic and print media appeared to have had an impact on the younger age groups and women in particular.

The findings support the use of electronic media in health promotional appeals against smoking. This is perhaps because these media are regarded as more effective in "emotional" as opposed to "intellectual" communications. As pointed out by Atkin, ${ }^{15}{ }^{16}$ logical appeals are superior for an intelligent, sophisticated audience. Emotional appeals, such as used in the electronic media in the current campaign, have the advantage of attracting the interest of indifferent persons, and are best suited for broadcast channels, dynamic sources, and affective change. The research also supports the effectiveness of the social marketing approach in this one area-that is, smoking. It remains to be seen if such an approach is as effective in topics such as nutrition education and exercise.
We thank Dr A Dobson, Professor S Leeder, Dr D Harris, Mr P Thornton, Mrs D Robson, Mrs D Montgomery, Dr A Binns, Ms L Plater, and Mrs L McPhee for valuable contributions to this work. The NSW Cancer Council, Australian Department of Health, and the Health Commission of NSW contributed to the funding of the campaign and its evaluation.

\section{References}

${ }^{1}$ Doll R, Hill AB. Lung cancer and other causes of death in relation to smoking. A second report on the mortality of British doctors. $\mathrm{Br} \mathrm{Med} \mathcal{F}$ 1956;ii:1071-81.

${ }^{2}$ US Surgeon General. Smoking and health. Washington, DC: US Department of Health, Education, and Welfare, 1979.

3 Thompson ELM. Smoking education programmes, 1960-1976. Am f Public Health 1978;68:250-7.

${ }^{4}$ McAlister A. Anti-smoking campaigns: progress in developing effective communications. In: Rice RE, Paisley WJ, eds. Public communication campaigns. California: Sage, 1981.

${ }^{5}$ Pechacek TF. Modification of smoking behaviour. Baltimore: National Institute of Drug Abuse, 1978.

${ }^{6}$ Farquhar J, Maccoby N, Solomon DS. Community applications of behavioural medicine. In: Gentry WD, ed. Handbook of behavioural medicine (in press).

' Puska P, Toumilehto J, Salonen J, et al. The North Karelia projects: evaluation of a comprehensive community programme for control of cardiovascular disease in 1972-1977 in North Karelia, Finland. Public health in Europe: Copenhagen: WHO/EURO Monograph Series, 1981.

${ }^{8}$ Farquhar J, Wood PD, Breitrose $\mathrm{H}$, et al. Community education for cardiovascular health. Lancet $1977 ;$ i:1192-5.

${ }^{9}$ Maccoby N, Solomon DS. The Stanford community studies in heart disease prevention. In: Rice R, Paisley W, eds. Public communication campaigns. California: Sage, 1981.

${ }^{10}$ Kotler P, Zaltman G. Social marketing; an approach to planned social change. Fournal of Marketing $1971 ; 35: 3-12$.

${ }^{11}$ Solomon D. A social marketing perspective on campaigns. In: Rice RE, Paisley WJ, eds. Public communication campaigns. California: Sage, 1981.

${ }^{12}$ Egger G, Frape G, Mackay B. Applied problems of media use in health promotion-the North Coast experience. New Doctor 1981 January: 25-9.

${ }^{13}$ Baker RJ, Nelder JA. GLIM manual. Oxford: Numerical Algorithms Group, 1978.

14 Nielsen AC, Pty Ltd. Nielsen omnibus survey. Sydney, Australia: AC Nielsen Pty Ltd, 1982.

15 Atkin C. Research evidence on mass mediated health communication campaigns. In: Nimmo D, ed. Communication yearbook 111. New Brunswick, NJ: Transaction Books, 1977.

${ }^{16}$ Atkin C. Mass media information campaign effectiveness. In: Rice RE, Paisley WJ, eds. Public communication campaigns. California: Sage, 1981.

(Accepted 19 fuly 1983)

A patient has been fitted with an artificial limb for an above knee amputation after injury. How of ten is he likely to need a new limb fitted?

How long an artificial limb will last depends on several factors. An artificial leg treated with some care and serviced regularly should last several years but a very active patient doing heavy work will wear his limb out more quickly than a relatively inactive older patient, probably within a year or so. An artificial limb can be used successfully only if the socket fits the stump correctly and if subsequently the dimensions of the stump remain stable. If at any time the stump changes the socket may need to be refitted or replaced. The need for expert servicing will depend on the form of construction of the limb. The modern trend is to build limbs on a modular basis, assembling them from a range of factory made metal and plastic components. Cosmesis is achieved by using plastic foam and a plastic skin. This type of limb needs servicing at a limb centre with the necessary facilities at least once a year. A patient without ready access to a limb fitting centre should have a limb that can be more readily serviced and repaired, such as a wooden limb with leather or webbing straps. These are the best choice because repairs and adjustments may be made by anyone, including the patient, with a modicum of experience in wood and leather work.- $\mathrm{R}$ G REDHEAD, senior medical officer, Limb Fitting Centre, Roehampton. 